\title{
Bulk FePt-based nanocomposite magnets with enhanced exchange coupling
}

\author{
Chuan-Bing Rong, Vikas Nandwana, Narayan Poudyal, and J. Ping Liu ${ }^{\text {a) }}$ \\ Department of Physics, University of Texas at Arlington, Arlington, Texas 76019 \\ Mikhail E. Kozlov and Ray H. Baughman \\ NanoTech Institute, University of Texas at Dallas, Richardson, Texas 75083 \\ Yong Ding and Zhong Lin Wang \\ School of Materials Science and Engineering, Georgia Institute of Technology, Atlanta, Georgia 30332
}

(Received 19 March 2007; accepted 2 June 2007; published online 23 July 2007)

\begin{abstract}
High density bulk $\mathrm{FePt} / \mathrm{Fe}_{3} \mathrm{Pt}$ nanocomposite magnets have been prepared by high-pressure warm compaction of chemically synthesized $\mathrm{FePt}$ and $\mathrm{Fe}_{3} \mathrm{O}_{4}$ nanoparticles. It is found that the density increases with the compaction pressure and temperature. Density of the bulk samples up to $95 \%$ theoretical value has been obtained while the nanostructured morphology is retained. It is also observed that a high pressure expedites the FePt phase transition from the disordered face-centered-cubic structure to the $L 1_{0}$ structure, leading to the phase transition temperature in the compacts one hundred degrees lower than usual. This phase transition in turn facilitates the consolidation of the compacts. Magnetic characterizations showed that interphase exchange coupling is enhanced upon the compaction. Post-annealing of the compacts results in further improved magnetic performance of the compacts owing to interface modification. Energy products up to 16.3 MG Oe of the isotropic bulk nanocomposite magnets have been achieved, which is significantly higher than the theoretical limit for fully dense single-phase FePt magnets. (c) 2007 American Institute of Physics.

[DOI: $10.1063 / 1.2756619]$
\end{abstract}

\section{INTRODUCTION}

Exchange-coupled hard/soft nanocomposite magnets have attracted great interest ${ }^{1-4}$ in the last decade because of their potential in achieving giant energy product $(\mathrm{BH})_{\max }$ that may be as large as $100 \mathrm{MG}$ Oe. ${ }^{5,6}$ Effective interphase magnetic exchange coupling in the nanocomposites can be achieved if dimensions of the soft-phase components are not larger than a nanoscale critical length. ${ }^{7-12}$ The grain size in nanocomposite magnets fabricated by conventional topdown methods, including mechanical alloying and rapid quenching, usually has a wide distribution, and can hardly be controlled below the critical length. An alternative bottom-up approach therefore is necessary to fabricate nanocomposite magnets with controllable nanoscale morphology. Recently, magnetic FePt nanoparticles synthesized by chemical solution methods have aroused significant attention because of their very small particle size and size distribution, which make them ideal building blocks for exchange-coupled nanocomposite bulk magnets. ${ }^{13-16}$ The biggest challenge for the bottom-up approach is how to produce bulk nanostructured magnets without losing the homogenous nanoscale morphology. Conventional compaction and condensation techniques cannot be applied for nanoparticles since those techniques require extensive heat treatments which lead to excessive grain growth. To date, there have been very limited data reported on direct compaction of intermetallic nanoparticles, especially for nanoparticles with size down to several na-

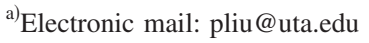

nometers. Recent attempts to fabricate bulk nanostructured magnets by using unconventional compaction techniques including plasma sintering and dynamic compaction ${ }^{17,18}$ have resulted limited success. Bulk samples with density up to $80 \%$ theoretical value have been obtained. The challenge remains in producing bulk nanostructured magnets with density close to theoretical values.

On the other hand, the as-synthesized FePt nanoparticles have the disordered face-centered cubic (fcc) structure with vanishing magnetocrystalline anisotropy. High temperature annealing (above $600{ }^{\circ} \mathrm{C}$ ) is necessary to obtain the ordered $L 1_{0}$ structure with very high magnetocrystalline anisotropy for hard magnetic applications. The challenge is how to avoid excessive particle or grain growth at such high temperatures. Adding third elements is one possibility to reduce the ordering temperature, while it inevitably decreases the magnetization which is harmful for applications as permanent magnets. ${ }^{23,24}$ Since the high pressure may reduce the phase transition temperature, ${ }^{25}$ the high-pressure warm compaction is therefore considered to be applicable to fabrication of nanoparticle based composite magnets.

High-pressure warm compaction is one of the advanced compaction techniques in powder metallurgy and has been widely used in automobile parts manufacturing in the past decade. ${ }^{19-22}$ This technique is established on the knowledge that metallic powders have better plasticity and compressibility at elevated temperatures and therefore are easier to be deformed to form high density bulks under a certain pressure, compared with cold pressing. Unlike hot pressing, 
warm compaction is performed at modest temperatures at which the metallic powders are chemically stable and no excessive grain growth occurs.

In this work, we report our recent results in preparation and characterization of bulk $\mathrm{FePt} / \mathrm{Fe}_{3} \mathrm{Pt}$ nanocomposite magnets by compacting chemically synthesized $\mathrm{FePt}$ and $\mathrm{Fe}_{3} \mathrm{O}_{4}$ nanoparticles at modest temperatures.

\section{EXPERIMENTAL}

The nanoparticles were synthesized by standard airless chemical solution procedures. ${ }^{13,26,27}$ The FePt with fcc structure and $\mathrm{Fe}_{3} \mathrm{O}_{4}$ nanoparticles were mixed at a mass ratio of $8: 1$ in a solution before centrifugation. The dried nanoparticles were heated under $\mathrm{Ar}$ atmosphere at $350{ }^{\circ} \mathrm{C}$ for $1 \mathrm{~h}$ to remove surfactants. The powders were then compacted with a warm-compaction press under pressure of 2.5 or $3.8 \mathrm{GPa}$ for $10 \mathrm{~min}$ at temperatures ranging from room temperature (about $20{ }^{\circ} \mathrm{C}$ ) to $600{ }^{\circ} \mathrm{C}$. The obtained bulk samples had dimensions $\phi 6 \mathrm{~mm} \times 1.5 \mathrm{~mm}$ and $\phi 3 \mathrm{~mm} \times 1.2 \mathrm{~mm}$ for the compaction pressures of 2.5 and $3.8 \mathrm{GPa}$, respectively. For comparison, we also compacted $15 \mathrm{~nm} L 1_{0}$ FePt nanoparticles prepared by the salt-matrix annealing technique ${ }^{16,28}$ at $2.5 \mathrm{GPa}$ pressure. The Archimedes method was employed for measurements of bulk sample density. The morphology and crystalline structure were characterized by scanning electron microscopy (SEM), transmission electron microscopy (TEM), and x-ray diffraction (XRD) using $\mathrm{Cu} K_{\alpha}$ radiation. The composition of the compacted samples were checked by energy dispersive x-ray (EDX) analysis in SEM. Magnetic properties were measured with superconducting quantum interference device magnetometer with a maximum applied field of $70 \mathrm{kOe}$.

\section{RESULTS AND DISCUSSIONS}

\section{A. Density}

It is known that the limit for density $\rho_{p}$ of a randomly packed particle system is only $64 \%$ if no deformation is involved. ${ }^{29}$ To obtain a higher $\rho_{p}$, it is necessary to realize plastic deformation of the particles. For nanoparticles, the deformation will not be as easy as for large particles because of the reduced dislocations in the particles, which explains low density values obtained in nanoparticle compacts. Figure 1 shows the dependence of $\rho_{p}$ of the bulk samples on the compaction temperature $\left(T_{\mathrm{cp}}\right)$ under different pressures. One can see that the density increased monotonously with compaction temperature for both fcc and $L 1_{0}$ particle compacts. The samples prepared at pressure $3.8 \mathrm{GPa}$ and $T_{\mathrm{cp}}$ of $600{ }^{\circ} \mathrm{C}$ has the highest density $\left(13.8 \mathrm{~g} / \mathrm{cm}^{3}\right)$ which is about $95 \%$ of the full density value $\left(14.5 \mathrm{~g} / \mathrm{cm}^{3}\right.$ for the $\mathrm{FePt} / \mathrm{Fe}_{3} \mathrm{Pt}$ composite with $15 \%$ volume fraction of $\mathrm{Fe}_{3} \mathrm{Pt}$ phase). Such high density is a result of a significant plastic deformation of the nanoparticles at the applied high pressure. A linear increase in the density can be observed for the $L 1_{0}$ particles in the whole studied temperature range and for the fcc particles in the temperature range from 20 to about $400{ }^{\circ} \mathrm{C}$. This may be explained by the fact that the yield strength of metallic FePt materials decreases linearly with temperature in the region between 20 and $800{ }^{\circ} \mathrm{C}$ (Ref. 30) and an effective lubrica-

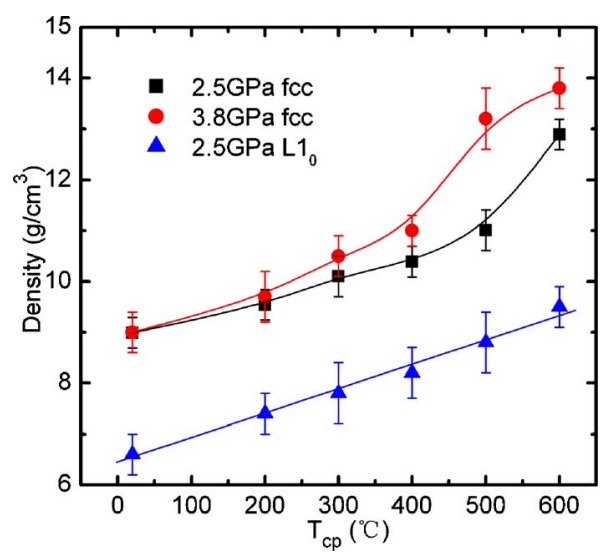

FIG. 1. (Color online) The dependence of density of the bulk samples on compaction temperature $T_{\mathrm{cp}}$.

tion mechanism can occur in the heated powders. ${ }^{19}$ However, this linear increase in density did not lead to full densification, even one extrapolate the curve to a high temperature.

Figure 1 shows that for the fcc nanoparticles, the dependence of $\rho_{p}$ on $T_{\mathrm{cp}}$ became steeper when $T_{\mathrm{cp}} \geq 400{ }^{\circ} \mathrm{C}$. This nonlinear behavior may be related to the phase transition from the disordered fcc to the ordered $L 1_{0}$ structure during which atoms are activated and become more mobile. The enhanced atomic diffusion promoted densification of the compacts and resulted in high density. On the other hand, the phase transition may also accelerate the formation of $\mathrm{Fe}_{3} \mathrm{Pt}$ phase in the $\mathrm{FePt}-\mathrm{Fe}_{3} \mathrm{O}_{4}$ nanoparticle system. ${ }^{14}$ Approximately $15 \%$ volume fraction of $\mathrm{Fe}_{3} \mathrm{Pt}$ phase was determined by using the method of Rietveld refinement of the XRD pattern which will be discussed later.

SEM analysis was performed on the fracture surfaces of the compacts to characterize morphological changes in the compacted samples. Figure 2 shows the typical SEM images of the bulk samples compacted at 20,400 , and $600{ }^{\circ} \mathrm{C}$. The $20{ }^{\circ} \mathrm{C}$-compacted samples are quite porous. With increasing $T_{\mathrm{cp}}$ to $400{ }^{\circ} \mathrm{C}$, it is interesting to find that stripes with thickness around 10-20 $\mu \mathrm{m}$ were formed. However, some small holes were still found in the layers. Compacting at $600{ }^{\circ} \mathrm{C}$ led to very large and homogenous areas $(>150 \mu \mathrm{m})$ in the compact and thus the high density. The SEM morphology change agrees with the dependence of density on compacted temperature as shown in Fig. 1.

\section{B. Phase transition}

As mentioned earlier, the rapidly increased density at the compaction temperature higher than $400{ }^{\circ} \mathrm{C}$ may be related to the phase transition of FePt component from fcc structure

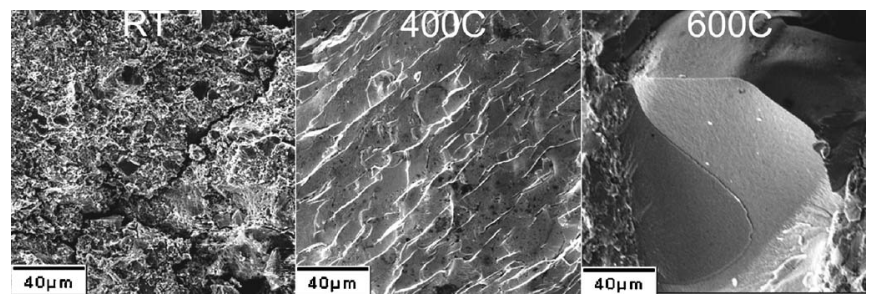

FIG. 2. SEM images of the bulk samples compacted at 20,400 , and $600{ }^{\circ} \mathrm{C}$. 


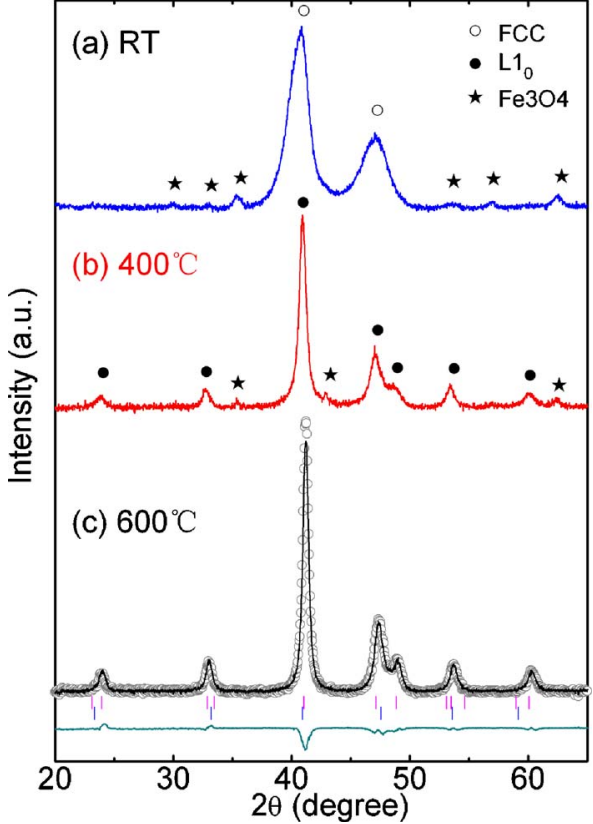

FIG. 3. (Color online) XRD patterns of the bulk samples compacted at (a) 20, (b) 400 , and (c) $600{ }^{\circ} \mathrm{C}$. The Rietveld refinement data are also included in (c) for the $600{ }^{\circ} \mathrm{C}$-compacted sample. The symbol (O) and full line represent the observed and calculated x-ray diffraction profiles, respectively. The vertical bars represent the Bragg reflection positions of the observed phases (from top to bottom: $L 1_{0} \mathrm{FePt}$ and $\mathrm{Fe}_{3} \mathrm{Pt}$ ). The difference curve is plotted in the bottom.

to the $L 1_{0}$ structure. To study the phase transition, we performed XRD measurement of the 20, 400, and $600{ }^{\circ} \mathrm{C}$-compacted samples and the patterns are shown in Fig. 3. It can be seen that the $20{ }^{\circ} \mathrm{C}$-compact mainly consists of fcc FePt and $\mathrm{Fe}_{3} \mathrm{O}_{4}$ phases. The compaction at $400{ }^{\circ} \mathrm{C}$ led to the phase transition of FePt component from fcc to $L 1_{0}$ structure while $\mathrm{Fe}_{3} \mathrm{O}_{4}$ was still existing. With increasing $T_{\mathrm{cp}}$ to $600{ }^{\circ} \mathrm{C}$, the $\mathrm{FePt}$ phase is of $L 1_{0}$ structure and the $\mathrm{Fe}_{3} \mathrm{O}_{4}$ disappeared. The quantitative analysis of the phase content can be made approximately by using the method of the Rietveld refinement on XRD patterns. ${ }^{31,32}$ As an example, the Rietveld refinement data of the $600{ }^{\circ} \mathrm{C}$ compact is also shown in Fig. 3. The SEM/EDX analysis shows the decrease of oxygen content from $13.7 \%$ for the $20{ }^{\circ} \mathrm{C}$-compacted sample to $5.0 \%$ for the $600{ }^{\circ} \mathrm{C}$-compacted sample based on big regions. Especially, the oxygen content decreases fast when $T_{\mathrm{cp}} \geq 400{ }^{\circ} \mathrm{C}$, which implies that the nanocrystalline $\mathrm{Fe}_{3} \mathrm{O}_{4}$ decomposed during the compaction at a temperature much lower than that reported in the literature. ${ }^{33}$ The TEM/ EDX analysis based on small regions confirms the existence $\mathrm{Fe}_{3} \mathrm{Pt}$ grains in the $600{ }^{\circ} \mathrm{C}$-compacted samples. The real cause for the decomposition of $\mathrm{Fe}_{3} \mathrm{O}_{4}$ remains to be understood and it may be related to the activated atoms diffusion during the phase transition of FePt component.

To evaluate the degree of phase transition from the disordered fcc to the ordered $L 1_{0}$ structure in a quantitative way, the chemical ordering parameter $S$ has been calculated by $S \cong 0.85\left[I_{001} / I_{002}\right]^{1 / 2}$ for the compacts and starting powders, where $I_{001}$ and $I_{002}$ are the integrated intensity of (001) and (002) XRD peaks of the $L 1_{0}$-FePt phase, respectively. ${ }^{34-36}$ Figure 4 gives the dependence of $S$ on the compaction tem-

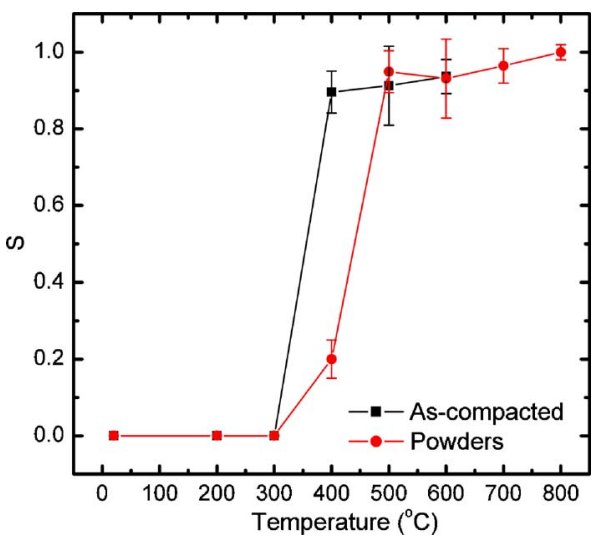

FIG. 4. (Color online) The dependence of $S$ on $T_{\mathrm{cp}}$ for the bulks. For comparison, the dependence of $S$ on annealing temperature of the starting powder is also included for $10 \mathrm{~min}$ annealing.

perature. It shows clearly that $S$ was almost zero when $T_{\text {cp }}$ $\leq 300{ }^{\circ} \mathrm{C}$ while it jumped to 0.9 at $T_{\mathrm{cp}}=400{ }^{\circ} \mathrm{C}$, indicating that the phase transition from fcc to $L 1_{0}$ was almost completed for the $400{ }^{\circ} \mathrm{C}$-compacted samples. For comparison, the dependence of $S$ on the annealing temperature of the starting powders is also given in Fig. 4, where the annealing time is $10 \mathrm{~min}$, which is same as the compacting time. It is interesting to note that the phase transition took place at a temperature $\left(\leq 400{ }^{\circ} \mathrm{C}\right)$ in the compacts lower than the powders and that reported for the FePt thin films (usually around $\left.600{ }^{\circ} \mathrm{C}\right) .{ }^{37}$ The presence of pressure should be responsible for the phase transition temperature shift. The expedited phase transition under high pressure is likely associated with the fact that the phase transition can be described as a compression of the fcc structure in the direction of the $c$ axis of the resulted tetragonal phase.

The phase transition is also confirmed by the dependence of magnetic properties on $T_{\mathrm{cp}}$. Figure 5 shows the dependence of saturation magnetization $M_{s}$ (measured in an applied field of $7 \mathrm{~T}$ ) and coercivity $H_{c}$ on $T_{\text {cp. }}$. The samples compacted at relatively low temperatures $\left(T_{\mathrm{cp}}<400{ }^{\circ} \mathrm{C}\right)$ showed nearly zero coercivity, while the $400{ }^{\circ} \mathrm{C}$-compacted sample gave $H_{c}$ of $10 \mathrm{kOe}$. The drastic increase in coercivity originated from the formation of the $L 1_{0}$ phase with high magnetocrystalline anisotropy. Since a higher $T_{\mathrm{cp}}$ led to a higher density of the compacts and thus a reduced surface effect, ${ }^{16,38}$ the $M_{s}$ value was increased from 850 to

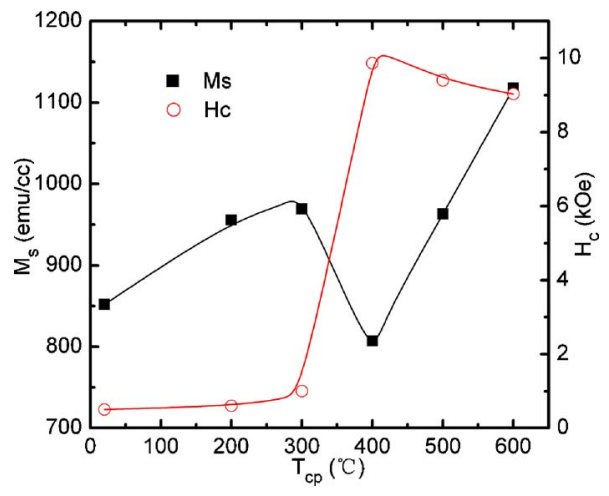

FIG. 5. (Color online) The dependence of $M_{s}$ and $H_{c}$ on $T_{\mathrm{cp}}$. 


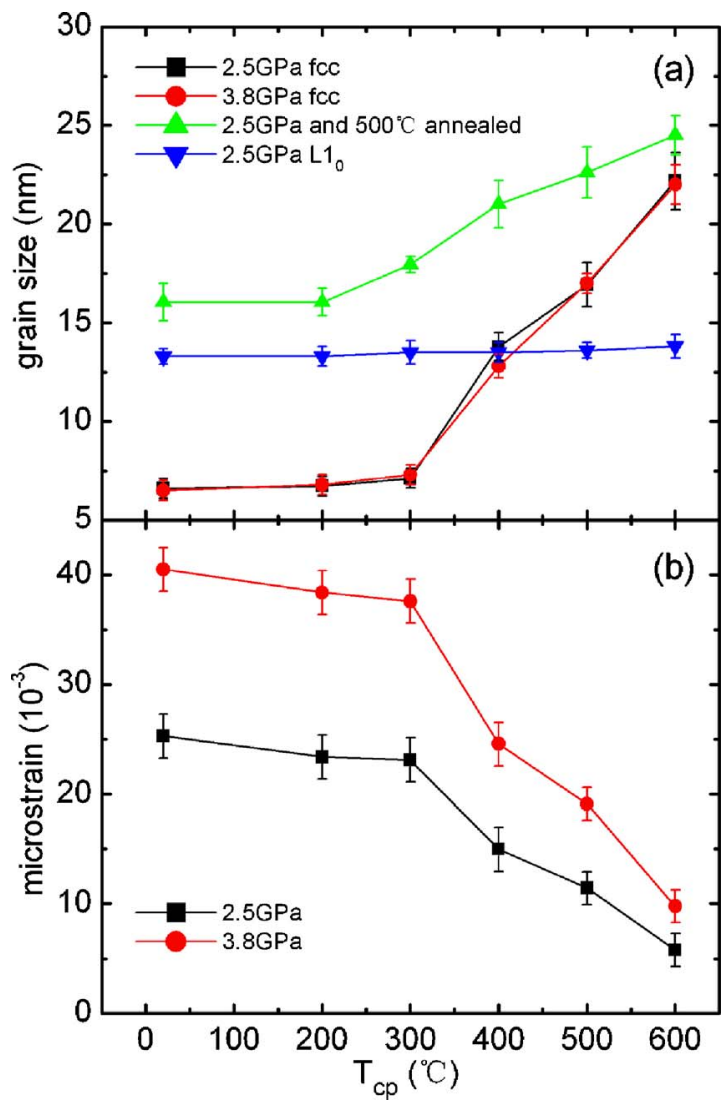

FIG. 6. (Color online) The dependence of grain size and microstrain on $T_{\mathrm{cp}}$ for as-compacted samples. The grain size of the annealed samples and the compacted $L 1_{0}$ nanoparticles are also given.

$970 \mathrm{emu} / \mathrm{cm}^{3}$ with increasing $T_{\mathrm{cp}}$ from 20 to $300{ }^{\circ} \mathrm{C}$. However, the $M_{s}$ dropped to $800 \mathrm{emu} / \mathrm{cm}^{3}$ at $T_{\mathrm{cp}}=400{ }^{\circ} \mathrm{C}$, which can be attributed to the phase transition since the antiparallel alignment of the polarized Pt spins to the Fe spins in the $L 1_{0}$ ordered FePt alloys and thus $M_{s}$ of the $L 1_{0}$ phase is lower than that of the fcc phase. ${ }^{39-41}$ Similar results were reported in Ref. 41, where the $M_{s}$ decreased by about $30 \%$ from $1000 \mathrm{emu} / \mathrm{cm}^{3}$ of the fcc phase to $670 \mathrm{emu} / \mathrm{cm}^{3}$ of the $L 1_{0}$ phase. Considering the $\mathrm{FePt} / \mathrm{Fe}_{3} \mathrm{O}_{4}$ mass ratio of $8: 1$ in our samples, the decrease of $M_{s}$ should be $23 \%$ if the fcc phase is completely transferred to the $L 1_{0}$ phase, which is in good agreement with the observed result. The further increase of $T_{\mathrm{cp}}$ resulted in a fast increase of $M_{s}$, due to the decomposition of magnetite and the formation of $\mathrm{Fe}_{3} \mathrm{Pt}$ phase during the compaction at relatively high temperature.

\section{Microstructural characteristics}

To quantitatively determine the effect of warm compaction on the microstructure, $\mathrm{x}$-ray diffraction line-broadening analysis was performed on the bulks. The grain size and retained strain were then determined using the WilliamsonHall analysis method. ${ }^{42}$ Figure 6 shows the dependence of grain size and microstrain on the compaction temperature for both 2.5 and $3.8 \mathrm{GPa}$-compacted samples. As one can see from Fig. 6(a), the grain size was almost unchanged (around $7 \mathrm{~nm}$ ) with temperature when $T_{\mathrm{cp}} \leq 300{ }^{\circ} \mathrm{C}$. However, the grain size increased linearly after that to $22 \mathrm{~nm}$ when $T_{\mathrm{cp}}$ $=600{ }^{\circ} \mathrm{C}$. It is interesting to note that the pressure has little

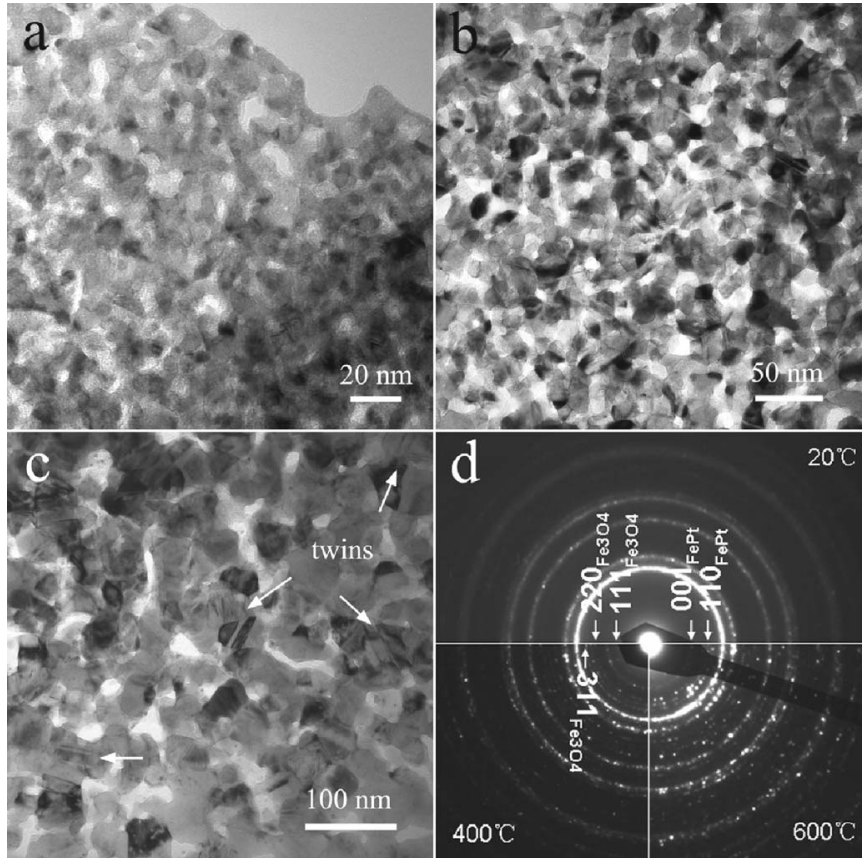

FIG. 7. TEM micrographs of bulk samples compacted at different temperatures. (a) 20, (b) 400 , (c) $600{ }^{\circ} \mathrm{C}$, and (d) SAED patterns at different temperatures.

effect on the grain size. On the other hand, it is obvious that the phase transition promoted grain growth which can be seen from the abrupt increase in grain size after the temperature was higher than $400{ }^{\circ} \mathrm{C}$. Nevertheless, the grain size is still under control in the nanoscale. It is also noted that a higher pressure led to a higher microstrain in the compacts and the microstrain was reduced with increasing temperature. When the temperature was increased to $T_{\mathrm{cp}} \geq 400{ }^{\circ} \mathrm{C}$, the microstrain was reduced quickly, as shown in Fig. 6(b), since the atomic rearrangement and atomic diffusion during the phase transition released the strain in the samples.

The grain size of bulk samples with post-annealing (compacted under $2.5 \mathrm{GPa}$ and annealed in forming gas at $500{ }^{\circ} \mathrm{C}$ for $1 \mathrm{~h}$ ) was also included in Fig. 6 to illustrate the effect of heat treatment on the morphology. It is found that the annealing led to the grain growth from 6.5 to $16 \mathrm{~nm}$ for the $20{ }^{\circ} \mathrm{C}$-compacted sample, while only from 22 to $25 \mathrm{~nm}$ for the $600{ }^{\circ} \mathrm{C}$-compacted sample, implying that the phase transition is the main reason for the grain growth. This is also evidenced by the observation that grain size of the $L 1_{0}$ nanoparticles was almost unchanged during the annealing. The compacts made by the $15 \mathrm{~nm} L 1_{0}$ nanoparticles showed no grain growth up to $600{ }^{\circ} \mathrm{C}$ (see Fig. 6). To confirm this observation, we heated the samples to $1000^{\circ} \mathrm{C}$ for $1 \mathrm{~h}$ and found that the average grain size was just slightly increased to about $17 \mathrm{~nm}$. The high stability of the $L 1_{0}$ structured nanoparticles can be utilized for fabrication of bulk nanocomposite magnets with very fine and homogenous nanoscale morphology.

Figure 7 shows the bright field TEM images of the bulk samples prepared from fcc nanoparticles under $2.5 \mathrm{GPa}$ pressure at 20,400 , and $600{ }^{\circ} \mathrm{C}$. The selected area electron diffraction patterns [Fig. 7(d)] confirm the phase transition. The TEM images show that grain size increases with $T_{\mathrm{cp}}$ as ex- 
pected. The grain size is about $7 \pm 3 \mathrm{~nm}$ and $14 \pm 5 \mathrm{~nm}$ for the 20 and $400{ }^{\circ} \mathrm{C}$-compacted samples, respectively. The grain size and size distribution are quite small compared to those for bulk materials fabricated by traditional techniques. This is in agreement with Fig. 6 that exhibits the dependence of average grain size on the compacting temperature. For the $600{ }^{\circ} \mathrm{C}$-compacted samples, TEM image shows the grain size is about $30 \pm 10 \mathrm{~nm}$, which is larger than that of XRD analysis. This should be attributed to the existence of large number of twin grains as marked in the Fig. 7(c).

\section{Exchange coupling and magnetic properties}

All the efforts in controlling grain size are made for the purpose to realize intergrain magnetic exchange coupling and thus to achieve high energy products. To study the magnetic interactions in the warm compaction-produced nanocomposite magnets, the $\delta m=m_{d}(H)-\left[1-2 m_{r}(H)\right]$ measurements (Henkel plots) were performed. ${ }^{4-45}$ Here $m_{d}$ is demagnetization remanence and $m_{r}$ is isothermal magnetization remanence. Both of these values are normalized by the saturation remanence. Nonzero $\delta m$ is caused by magnetic interactions between particles or grains. The positive $\delta m$ is interpreted as a sign for magnetic exchange coupling and the negative $\delta m$ is a sign of magnetic dipolar interaction. Figure $8(a)$ shows $\delta m$ plots of 400 and $600{ }^{\circ} \mathrm{C}$-compacted samples prepared from the fcc particles. The $\delta m$ value for the $600{ }^{\circ} \mathrm{C}$-compacted sample is positive and much higher than that for the $400{ }^{\circ} \mathrm{C}$-compacted sample, indicating stronger exchange coupling in the compact compared to the $400{ }^{\circ} \mathrm{C}$-compacted samples with lower density. This is also reflected by the shape of the hysteresis loops, as shown in the inset of Fig. 8(a). The remanence ratio $\left(M_{r} / M_{s}=0.63\right.$, where $M_{r}$ is the remanent magnetization) of the $600{ }^{\circ} \mathrm{C}$-compacted sample is higher than that of the $400{ }^{\circ} \mathrm{C}$ compacted (0.58), which is also consistent with the $\delta m$ measurement. This effect is even more pronounced for the $L 1_{0}$ particle samples. Figure 8(b) shows the Henkel plots for $15 \mathrm{~nm} L 1_{0}$ nanoparticles and their compacts. $\delta m$ for them before compaction is a large negative value. After the compaction at $2.5 \mathrm{GPa}$ and $200{ }^{\circ} \mathrm{C}, \delta m$ changed its sign to positive, indicating an interparticle exchange interaction. Annealing of the compact at $1000{ }^{\circ} \mathrm{C}$ for $1 \mathrm{~h}$ led to further increase in $\delta m$ value and thus an enhancement of the exchange coupling. As the annealing causes almost no obvious grain growth, the strong increase in $\delta m$ can be attributed to improvement in interface conditions upon the high temperature annealing. This result is consistent with the results reported in Ref. 46. The inset in Fig. 8(b) gives the hysteresis loops of the $L 1_{0}$ nanoparticles and its compacts. It shows that the enhanced exchange coupling significantly improves the squareness of the hysteresis loops and therefore the energy products. A (BH) $\max$ about 15.6 MG Oe has been obtained based on the measurement from the real density.

The magnetic properties can be further improved by a post-annealing under forming gas $\left(93 \% \mathrm{Ar}+7 \% \mathrm{H}_{2}\right)$ for $1 \mathrm{~h}$. Figure 9 shows the effect of annealing temperature $\left(T_{a}\right)$ on $M_{s}, H_{c}$, and $(\mathrm{BH})_{\max }$ of the 20,400 , and $600{ }^{\circ} \mathrm{C}$ compacts. As shown in Fig. 9(a), $M_{s}$ of the 20 and $400{ }^{\circ} \mathrm{C}$ compacts

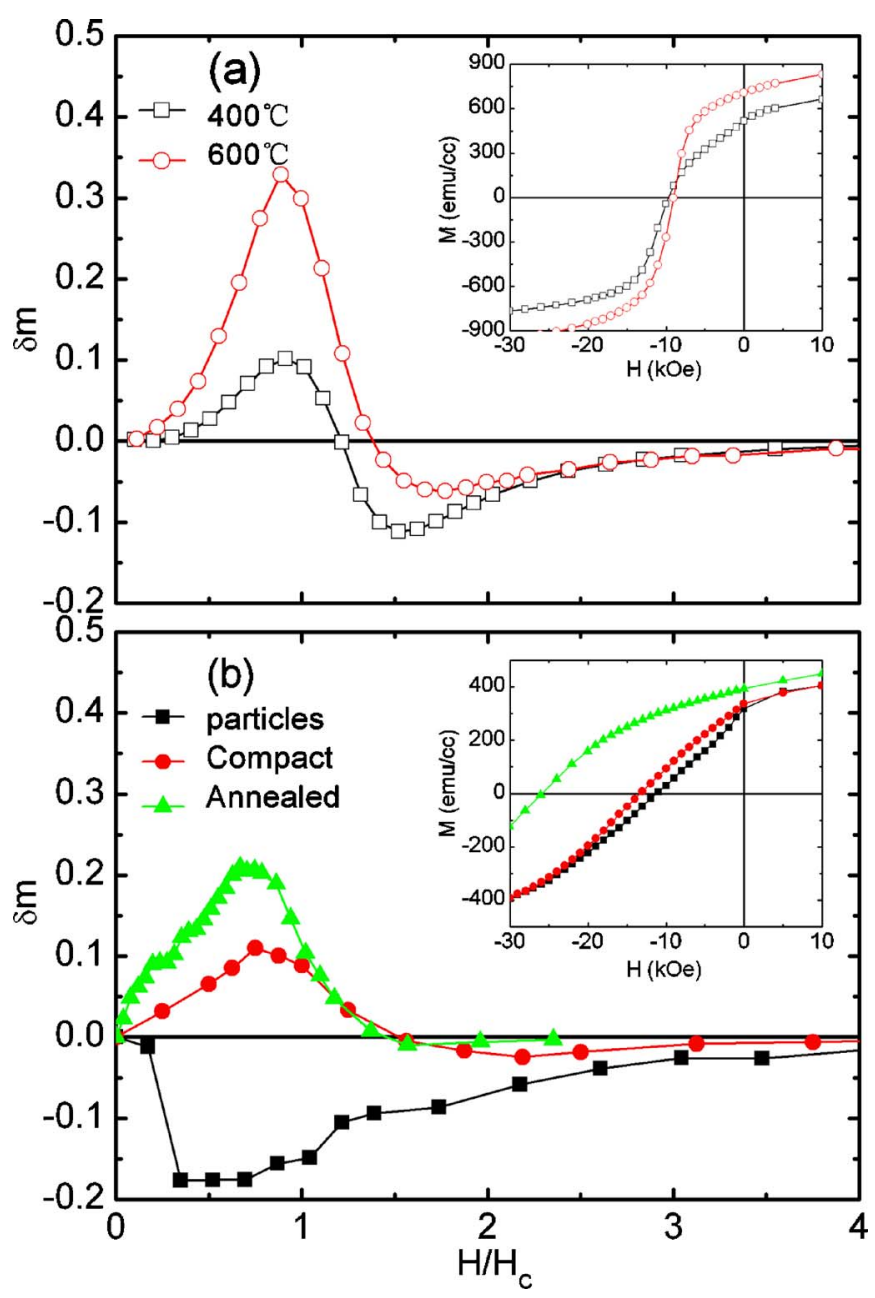

FIG. 8. (Color online) (a) $\delta m$ plots of the samples compacted at 400 and $600{ }^{\circ} \mathrm{C}$ from the fcc nanoparticles. (b) $\delta m$ plots of the separated $L 1_{0}$ particles and samples compacted (at $2.5 \mathrm{GPa}, 200{ }^{\circ} \mathrm{C}$ ) from the $L 1_{0}$ nanoparticles as well as the post-annealed bulk samples. The insets are the corresponding demagnetization curves.

increased significantly after the annealing. This was attributed to the decomposition of $\mathrm{Fe}_{3} \mathrm{O}_{4}$ phase and the formation of $\mathrm{Fe}$ or $\mathrm{Fe}_{3} \mathrm{Pt}$ with high magnetization in the reducing atmosphere. $M_{s}$ value up to $1140 \mathrm{emu} / \mathrm{cm}^{3}$ can be obtained by post-annealing. However, it is found that $M_{s}$ of the $600{ }^{\circ} \mathrm{C}$-compacted sample had a very small change upon post-annealing. This may be due to the early formation of $\mathrm{Fe}_{3} \mathrm{Pt}$ phase during the warm compaction as discussed early. For all the samples compacted at the three temperatures, high-temperature annealing $\left(>600^{\circ} \mathrm{C}\right)$ led to a decrease in $M_{s}$, which may be related to the atomic diffusion between FePt and $\mathrm{Fe}_{3} \mathrm{Pt}^{32}$ As shown in Fig. 9(b), $H_{c}$ of the $20{ }^{\circ} \mathrm{C}$-compacted samples increases fast when $T_{a}$ is higher than $450{ }^{\circ} \mathrm{C}$ which shows that the phase transition from fcc to $L 1_{0}$ resulted in magnetic hardening. For the 400 and $600{ }^{\circ} \mathrm{C}$-compacted samples, post-annealing did not improve the $H_{c}$ since the phase transition had already happened during the warm compaction. In this case, high-temperature annealing led to an overgrowth in grain size and therefore deterioration in the magnetic properties. By optimizing the post-annealing parameters further improvement of the $(\mathrm{BH})_{\max }$ up to $16.3 \mathrm{MG}$ Oe (based on the real density for 


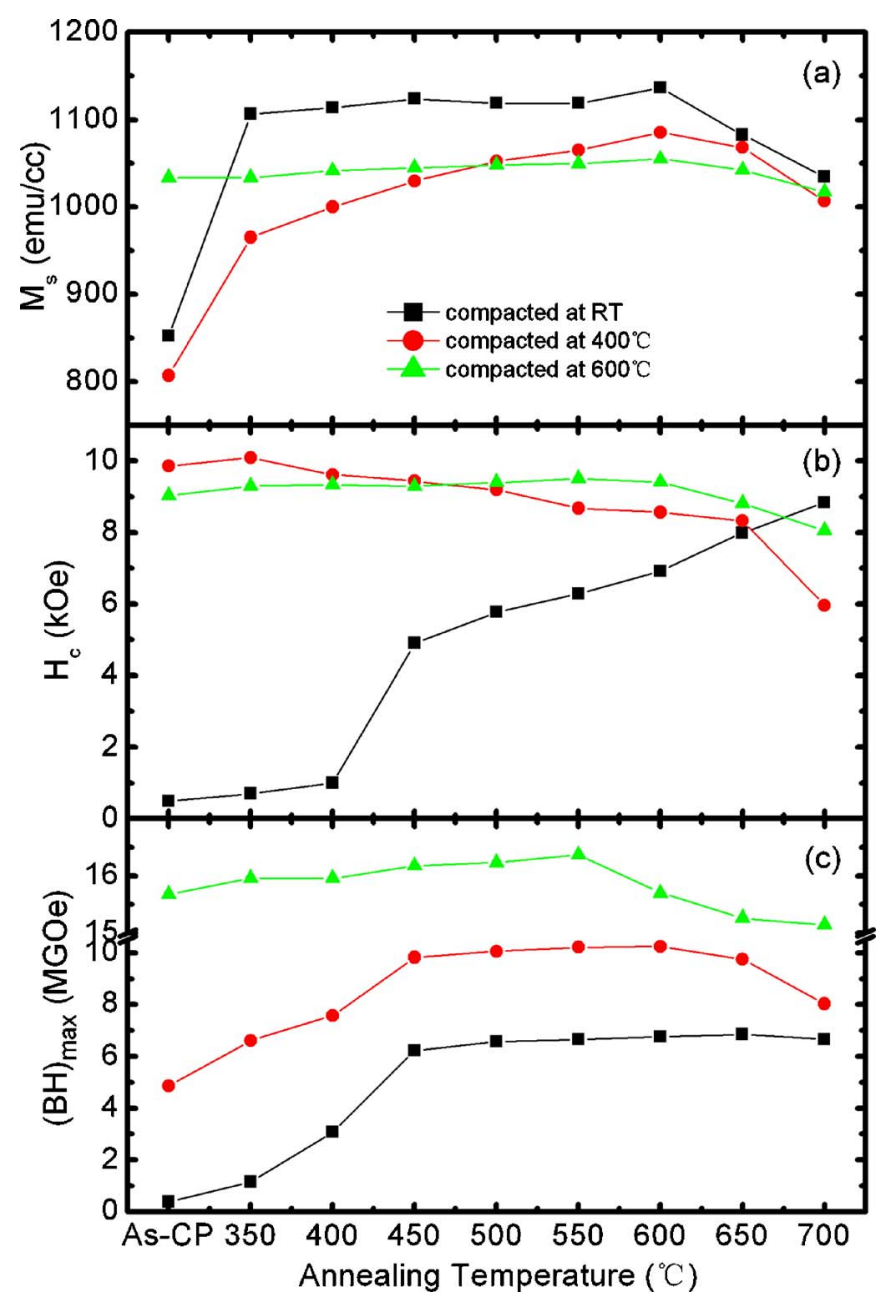

FIG. 9. (Color online) The dependence of $M_{s}, H_{c}$, and $(\mathrm{BH})_{\max }$ on the annealing temperature for 20,400 , and $600{ }^{\circ} \mathrm{C}$-compacted samples.

$600{ }^{\circ} \mathrm{C}$ compact) has been achieved which is significantly higher than the theoretical limit (13 MG Oe) for the singlephase isotropic FePt magnets.

\section{CONCLUSIONS}

In summary, high density $\mathrm{FePt} / \mathrm{Fe}_{3} \mathrm{Pt}$ bulk nanocomposite magnets have been obtained by the warm compaction method. A density up to $95 \%$ of the full density has been achieved while the nanoscale morphology is retained. Effective exchange coupling in the high-density bulk samples is realized. It is found that the pressure expedites the fcc- $L 1_{0}$ phase transition. The phase transition temperature shifts to a temperature lower than $400{ }^{\circ} \mathrm{C}$ under $2.5 \mathrm{GPa}$ pressure. The phase transition has a positive effect on consolidation of the compacts. It has also been observed that the $L 1_{0}$ nanoparticles have high stability during heat treatments. Followed by a proper post-annealing treatment, magnetic properties of bulk samples can be significantly improved. Our results show that warm compaction technique is promising for producing high performance bulk nanocomposite magnets for advanced applications.

\section{ACKNOWLEDGMENTS}

This work was supported by U.S. DoD/MURI Grant No. N00014-05-1-0497 and DARPA through USARO under Grant No. DAAD 19-03-1-0038. The work at University of Texas at Dallas was supported by the Robert A. Welch Foundation Grant No. AT-0029.

${ }^{1}$ R. Coehoorn, D. B. de Mooij, and C. de Waard, J. Magn. Magn. Mater. 80, 101 (1989).

${ }^{2}$ A. Manaf, R. A. Buckley, and H. A. Davies, J. Magn. Magn. Mater. 128, 302 (1993).

${ }^{3}$ G. C. Hadjipanayis, J. Magn. Magn. Mater. 200, 373 (1999).

${ }^{4}$ J. Zhang, S. Y. Zhang, H. W. Zhang, and B. G. Shen, J. Appl. Phys. 89, 5601 (2001).

${ }^{5}$ R. Skomski and J. M. D. Coey, Phys. Rev. B 48, 15812 (1993).

${ }^{6}$ C. B. Rong, H. W. Zhang, R. J. Chen, S. L. He, and B. G. Shen, J. Magn. Magn. Mater. 302, 126 (2006).

${ }^{7}$ E. Kneller and R. Hawig, IEEE Trans. Magn. 27, 3588 (1991).

${ }^{8}$ Z. J. Guo, J. S. Jiang, J. E. Pearson, S. D. Bader, and J. P. Liu, Appl. Phys. Lett. 81, 2029 (2002).

${ }^{9}$ Z. S. Shan, J. P. Liu, M. Vamsi Chakka, H. Zeng, and J. S. Jiang, IEEE Trans. Magn. 38, 2907 (2002).

${ }^{10}$ C. B. Rong, H. W. Zhang, X. B. Du, J. Zhang, S. Y. Zhang, and B. G. Shen, J. Appl. Phys. 96, 3921 (2004).

${ }^{11}$ R. Skomski, J. Phys.: Condens. Matter 15, R841 (2003).

${ }^{12}$ A. J. Zambano, H. Oguchi, I. Takeuchi, Y. Choi, J. S. Jiang, J. P. Liu, S. E. Lofland, D. Josell, and L. A. Bendersky, Phys. Rev. B 75, 144429 (2007).

${ }^{13}$ S. H. Sun, C. B. Murray, D. Weller, L. Folks, and A. Moser, Science 287, 1989 (2000).

${ }^{14}$ H. Zeng, J. Li, J. P. Liu, Z. L. Wang, and S. H. Sun, Nature (London) 420, 395 (2002).

${ }^{15}$ M. Chen, J. P. Liu, and S. H. Sun, J. Am. Chem. Soc. 126, 8394 (2004).

${ }^{16}$ C. B. Rong, D. Li, V. Nandwana, N. Poudyal, Y. Ding, Z. L. Wang, H. Zeng, and J. P. Liu, Adv. Mater. 18, 2984 (2006).

${ }^{17}$ C. B. Rong, V. Nandwana, N. Poudyal, J. P. Liu, T. Saito, Y. Q. Wu and M. J. Kramer, J. Appl. Phys. 101, 09K515 (2007).

${ }^{18}$ C. D. Dai, D. Eakins, N. Thadhani, and J. P. Liu, Appl. Phys. Lett. 90, 071911 (2007).

${ }^{19}$ H. G. Rutz, F. G. Hanejko, and S. H. Luk, Met. Powder Rep. 49, 40 (1994).

${ }^{20}$ G. E. Fougere, J. R. Weertman, and R. W. Siegel, Nanostruct. Mater. 5, 127 (1995)

${ }^{21}$ G. F. Bocchini, Powder Metall. 42, 171 (1999).

${ }^{22}$ K. Kondoh, T. Takikawa, and R. Watanabe, J. Jpn. Soc. Powder Powder Metall. 47, 941 (2000).

${ }^{23}$ S. Kang, Z. Jia, and D. E. Nikles, Nano Lett. 2, 1033 (2002).

${ }^{24}$ Q. Yan, T. Kim, A. Purkayastha, P. G. Ganesan, M. Shima, and G. Ramanath, Adv. Mater. 17, 2233 (2005).

${ }^{25}$ S. B. Qadri, E. F. Skelton, A. W. Webb, N. Moulton, J. Z. Hu, and J. K. Furdyna, Phys. Rev. B 45, 5670 (1992).

${ }^{26}$ S. H. Sun, H. Zeng, D. B. Robinson, S. Raoux, P. M. Rice, S. X. Wang, and G. X. Li, J. Am. Chem. Soc. 126, 273 (2004).

${ }^{27}$ C. B. Rong, Y. Li, and J. P. Liu, J. Appl. Phys. 101, 09K505 (2007).

${ }^{28}$ K. Elkins, D. Li, N. Poudyal, V. Nandwana, Z. Jin, K. Chen, and J. P. Liu, J. Phys. D 38, 2306 (2005).

${ }^{29}$ H. M. Jaeger and S. R. Nagel, Science 255, 1523 (1992).

${ }^{30}$ S. H. Whang, Q. Feng, and Y. Q. Gao, Acta Mater. 46, 6485 (1998).

${ }^{31}$ J. Lyubina, I. Opahle, K. H. Muller, O. Gutfleisch, M. Richter, M. Wolf, and L. Schultz, J. Phys.: Condens. Matter 17, 4157 (2005).

${ }^{32}$ C. B. Rong, V. Nandwana, N. Poudyal, Y. Li, J. P. Liu, Y. Ding, and Z. L. Wang, J. Phys. D 40, 712 (2007).

${ }^{33}$ N. N. Greenwood and A. Earnshaw, Chemistry of the Elements (Butterworths/Heinemann, Oxford, 1997).

${ }^{34}$ B. E. Warren, X-Ray Diffraction (Dover, New York, 1990), Chap. 12.

${ }^{35}$ J. A. Christodoulides, P. Farber, M. Daniil, H. Okumura, G. C. Hadjipanayis, V. Skumryev, A. Simopoulos, and D. Weller, IEEE Trans. Magn. 37, 1292 (2001).

${ }^{36}$ S. H. Whang, Q. Feng, and Y. Q. Gao, Acta Mater. 46, 6485 (1998).

${ }^{37}$ Y. K. Takahashi, T. Ohkubo, M. Ohnuma, and K. Hono, J. Appl. Phys. 93, 7166 (2003).

${ }^{38}$ Z. X. Tang, C. M. Sorensen, K. J. Klabunde, and G. C. Hadjipanayis, Phys. Rev. Lett. 67, 3602 (1991). 
${ }^{39}$ A. Z. Men'shikov, Y. A. Dorofeev, V. A. Kazantsev, and S. K. Sidorov, Fiz. Met. Metalloved. 38, 505 (1974).

${ }^{40}$ T. Katayama, T. Sugimoto, Y. Suzuki, M. Hashimoto, P. de Haan, and J. C. Lodder, J. Magn. Magn. Mater. 104-107, 1002 (1992).

${ }^{41}$ S. C. Chen, P. C. Kuo, S. T. Kuo, A. C. Sun, C. Y. Chou, and Y. H. Fang, IEEE Trans. Magn. 41, 915 (2005).

${ }^{42}$ K. Williamson and W. H. Hall, Acta Metall. 1, 22 (1953).

${ }^{43}$ K. O'Grady, M. El-Hilo, and R. W. Chantrell, IEEE Trans. Magn. 29,
2608 (1993)

${ }^{44}$ A. Bollero, O. Gutfleisch, K.-H. Muller, L. Schultz, and G. Drazic, J. Appl. Phys. 91, 8159 (2002).

${ }^{45}$ C. B. Rong, H. W. Zhang, B. G. Shen, and J. P. Liu, Appl. Phys. Lett. 88, 042504 (2006).

${ }^{46}$ J. S. Jiang, J. E. Pearson, Z. Y. Liu, B. Kabius, S. Trasobares, D. J. Miller, S. D. Bader, D. R. Lee, D. Haskel, G. Srajer, and J. P. Liu, Appl. Phys. Lett. 85, 5293 (2004). 